\title{
Socioeconomic Variables Responsible for Exclusively Diabetes Among Bangladeshi Adults
}

\section{KC Bhuyan*}

Professor of Statistics, Jahangirnagar University, Dhaka, Bangladesh

*Corresponding Author: KC Bhuyan, Professor of Statistics, Jahangirnagar

University, Dhaka, Bangladesh.

DOI: $10.31080 /$ ASNH.2020.04.0644
Received: November 25, 2019

Published: February 14, 2020

(c) All rights are reserved by KC Bhuyan.

\begin{abstract}
The information provided here were analytical results of data collected from 808 adults who were interviewed by some doctors and nurses from their working places according to their convenience. Among the investigated adults 27.7 percent were exclusively suffering from diabetes which is one of the component of non-communicable diseases. An earlier study provided the information that 36.3 percent urban adults were suffering from this disease. In this study, 84.2 percent adults were urban residents and 25 percent of them were suffering exclusively from diabetes. But, urban and rural adults were at similar risk of prevalence of diabetes. The important reasons for the sufferings from diabetes were family income and marital status followed by expenditure, age and occupation. These variables were detected by factor analysis as factor loadings of these variables were higher.

Keywords: Diabetes; Socioeconomic Variables; Risk Ratio; Factor Analysis; Factor Loading
\end{abstract}

\section{Introduction}

Diabetes is a disease originated from insulin deficiency when pancreas is no longer able to make insulin or when the body cannot make use of the insulin it produces. Due to diabetes people have an increased risk of developing a number of health hazards like heart and blood vessels, eyes, kidneys, nerves and teeth. This disease is a leading cause of cardiovascular disease (CVD), chronic kidney disease (CKD), blindness and lower limb amputation.

It was reported that approximately 463 million adults of ages 20 - 79 years worldwide were diabetic [1]. This figure will be increased up to 700 million in 2045. Proportion of type 2 diabetes is increasing in most countries and 79 percent of adults with diabetes were living in low and middle-income countries [1]. Most of the diabetic people were in the age group 40 - 59 years and 374 million people are at risk of developing type 2 diabetes [1]. In another report it was mentioned that 1 in 5 diabetic patients were at the age above 65 years and 2 in 3 were urban residents [2,3]. Every year 4.2 million deaths were also reported [1]. The risk of diabetes among adults were also reported in different studies of home and abroad [4-11].

In one study, it was observed that most of the Bangladeshi urban adults (36.3\%) were suffering from diabetes [4]. The prevalence of diabetes in adults of ages 20 - 79 years was 7.4 percent in Bangladesh $[4,5]$. According to IDF the prevalence will be 13 percent by 2030 [3]. Diabetes was the targeted disease by WHO as it has some economic consequences also [9,10].

The earlier studies provided information that diabetes was the major health problem among Bangladeshi adults [11-13] and it was associated with obesity and some of the socioeconomic vari- ables $[12,13]$. The present study was an attempt to investigate the risk and responsible factors of diabetes among adults of Bangladesh. The specific objectives were

- To investigate the risk factors of diabetes,

- To detect the responsible factors for diabetes.

\section{Methodology}

The data for the present analysis were collected from 808 adults of Bangladesh by a group of doctors and nurses from their working places or nearby residences according to convenient sampling plan during academic session 2016 - 17 . The investigators were instructed to collect information from the persons who were 18 years and above during investigation. The data were recorded through a pre-designed and pre-tested printed questionnaire. The recorded data were related to different socioeconomic variables of the respondents including the information of prevalence of different types of non-communicable diseases, treatment of diseases, expenditure for treatment, duration of stay in hospital for treatment of NCDs, etc. Some of the variables were qualitative in character. But for analytical purpose all the variables were measured in nominal scores.

In some studies, both in home and abroad, it was noted that diabetes were associated with level of obesity [5,11-14]. Again, level of obesity was measured by body mass index (BMI). The BMI was measured by weight in $\mathrm{kg} /$ (height in meter) $2[2,15,16]$. The adults were classified as underweight $[\mathrm{BMI}<20]$, normal $[\mathrm{BMI}=20-<$ $25]$, overweight [BMI= $25-<30]$, and obese [BMI $\geq 30]$ [2].

The adults were divided into two groups, one group were exclusively suffering from diabetes. In this group there were 224 adults. Rest of the adults were either free of any disease or were suffering 
from multiple diseases. The association of socioeconomic variables with prevalence of diabetes when adults were classified as diabetic and non-diabetic was investigated by Chi - square test, where significant association was decided if $\mathrm{p}$ - value of any test statistic was $<0.05$. The risk ratio was calculated for all dichotomous data [17]. Factor analysis was done to detect the most responsible factor for diabetes. Higher factor loading of any variable indicates the more responsible variable for diabetes [11,18-20].

\section{Result}

It was mentioned that the total investigated adults was 808 . Among these adults, 84.2 percent [Table 1] were from urban area and 25 percent of them were suffering exclusively from diabetes. The percentage of adults in the sample suffering from diabetes was 27.7. However, there was no significant differences in the percentages of diabetic patients of urban and rural areas $\left[\chi^{2}=0.563\right.$, pvalue $=0.453]$. The risk ratio 0.89 indicated that both urban and rural adults were almost at similar risk of diabetes.

The percentage of male adults was 69.7 and 25.9 percent of them were exclusively diabetic patients. The female diabetic patients was 31.8 percent and they had 22 percent more risk of diabetes compared to the risk of male adults [Risk Ratio, R.R.=1.22]. However, there was no significant association between gender variation and variation in the prevalence of diabetes $\left[\chi^{2}=2.970\right.$, $\mathrm{p}$-value $=0.085]$.

The percentage of Muslim respondents was 89.9 and 28.4 percent of them were diabetic patients. The percentage of non -Muslim diabetic patients was 22.0. But this differential percentages of diabetic patients between two religious groups were not statistically significant $\left[\chi^{2}=1.517, \mathrm{p}\right.$-value $\left.=0.218\right]$ though the Muslims adults were at more risk of diabetes by 29 percent [R.R.=1.29].

The percentage of married adults was 50.9 and 31.9 percent of them were suffering from diabetes and they were at high risk of diabetes compared to the risk of single adult [R.R.=1.36].

There were significant differences in the percentages of diabetic adults of males and females $\left[\chi^{2}=7.901, p\right.$-value $\left.=0.019\right]$.

Significant differences in the proportions of diabetic adults of different age groups $\left[\chi^{2}=13.201, \mathrm{p}\right.$-value $\left.=0.010\right]$ were also observed. The adults of ages 40 years and above were at 28 percent more risk of diabetes compared to the risk of adults of ages less than 40 years [R.R.=1.28].

The percentage of higher educated adults was 74.4 and 26.6 percent of them were exclusively suffering from diabetes. This percentage among illiterate adults was 40.9. But the differences in percentages of diabetic adults of different levels of education were not significant $\left[\chi^{2}=5.064\right.$, p-value $=0.167$. However, the illiterate adults were at higher risk of diabetes by an amount 50.0 percent compared to the risk of educated adults [R.R.=1.50].

The adults were classified by agriculturists and unskilled labors, businessmen and skilled labors, service persons and others in- cluding housewives [21]. The percentages of these 4 occupational groups of adults were 4.3, 9.4, 22.6 and 63.6, respectively. Higher proportion of businessmen and skilled labors (34.2\%) were diabetic patients. Lower percentage $(8.6 \%)$ of diabetic patients was observed among agriculturists and unskilled labors. The differentials in percentages of diabetic patients of different occupational groups of adults were significant as was observed by chi-square test $\left[\chi^{2}=9.942\right.$, $p$-value $\left.=0.019\right]$. The risk of diabetes among different professional groups compared to the risk of agriculturists and unskilled labors was more than 3 times [R.R.=3.34].

Maximum (33.9\%) diabetic patients was observed in those families where monthly family income was 60 thousand and above but less than 90 thousands. But a big group of adults (58.3\%) were coming from highest income group of families (taka 90 thousands and above). Diabetic patients in this group was 28.5 percent. This percentage of diabetic patients was almost similar to the percentage of diabetic patients in the families having income 30 thousands to less than 60 thousands. However, there was no significant difference in the proportions of diabetic patients of different income groups of adults $\left[\chi^{2}=0.373\right.$,p-value $\left.=0.338\right]$. The risk of diabetes among most rich adults compared to the risk of adults of other income groups were almost similar [R.R $=1.06]$. The risk is slightly higher [R.R.= 1.05] among the adults of middle income families.

Families of a big group (35.6\%) of adults were experienced of highest family expenditure (taka 60 thousands and above). But lowest percentage $(23.6 \%)$ of diabetic patients was observed in these families. The differences in the proportions of diabetic patients of families spending different amounts of money were significant $\left[\chi^{2}=14.572\right.$, $\mathrm{p}$-value $\left.=0.002\right]$. Adults of families spending middle level of money as family expenditure [taka 40 - 60 thousands] were at higher risk of diabetes compared to the risk of adults of other groups [R.R.=1.49].

Only 4.3 percent adults were obese but 40 percent of them were suffering from diabetes. Lowest percentage $(21.5 \%)$ of diabetic patients was noted among underweight adults. Though insignificant association between level of obesity and prevalence of diabetes was noted $\left[\chi^{2}=5.773\right.$, p-value $\left.=0.123\right]$, still overweight and obese adults were at higher risk of diabetes by an amount 23 percent compared to the risk of adults of other two levels of obesity [R.R.=1.23].

Longer duration of use of mobile phone and watching T.V. for long time are sedentary activities. By doing these two activities 46.5 percent adults were spending their times and higher proportions of them were suffering from diabetes (30.9\%). Surprisingly enough, a big group of adults involved in games and sports were diabetic patients $(37.5 \%)$. In this group there were only 6.9 percent adults. However, prevalence of diabetes was not dependent on the utilization of time by the adults $\left[\chi^{2}=8.714\right.$, $\mathrm{p}$ - value $\left.=0.069\right]$. Though insignificant association between prevalence of diabetes and utilization of time was noted, still the adults involved in sedentary activities were at higher risk of diabetes compared to the 


\begin{tabular}{|c|c|c|c|c|c|c|}
\hline \multirow{3}{*}{ Socioeconomic variables } & \multicolumn{4}{|c|}{ Prevalence of exclusively diabetes } & \multirow{2}{*}{\multicolumn{2}{|c|}{ Total }} \\
\hline & \multicolumn{2}{|c|}{ Yes } & \multicolumn{2}{|c|}{ No } & & \\
\hline & $\mathbf{N}$ & $\%$ & $\mathbf{N}$ & $\%$ & $\mathbf{n}$ & $\%$ \\
\hline \multicolumn{7}{|l|}{ Residence } \\
\hline Rural & 32 & 25.0 & 96 & 75.0 & 128 & 15.8 \\
\hline Urban & 192 & 28.2 & 488 & 71.8 & 680 & 84.2 \\
\hline Total & 224 & 27.7 & 584 & 72.7 & 808 & 100.0 \\
\hline \multicolumn{7}{|l|}{ Gender } \\
\hline Male & 146 & 25.9 & 417 & 74.1 & 563 & 69.7 \\
\hline Female & 78 & 31.8 & 167 & 68.2 & 245 & 30.3 \\
\hline \multicolumn{7}{|l|}{ Religion } \\
\hline Muslim & 206 & 28.4 & 520 & 71.6 & 726 & 89.9 \\
\hline Non-Muslim & 18 & 22.0 & 64 & 78.0 & 82 & 10.1 \\
\hline \multicolumn{7}{|l|}{ Marital status } \\
\hline Currently married & 131 & 31.9 & 280 & 68.1 & 411 & 50.9 \\
\hline Currently single & 93 & 23.4 & 304 & 76.6 & 397 & 49.1 \\
\hline \multicolumn{7}{|l|}{ Age ( in years) } \\
\hline$<20$ & 11 & 30.6 & 25 & 69.4 & 36 & 4.5 \\
\hline $20-30$ & 81 & 26.0 & 231 & 74.0 & 312 & 38.6 \\
\hline $30-40$ & 9 & 13.6 & 57 & 86.4 & 66 & 8.2 \\
\hline $40-50$ & 35 & 25.4 & 103 & 74.6 & 138 & 17.1 \\
\hline $50^{+}$ & 88 & 34.4 & 168 & 65.6 & 266 & 32.9 \\
\hline \multicolumn{7}{|l|}{ Education } \\
\hline Illiterate & 9 & 40.9 & 13 & 59.1 & 22 & 2.7 \\
\hline Primary & 21 & 37.5 & 35 & 62.5 & 56 & 6.9 \\
\hline Secondary & 34 & 26.4 & 95 & 73.6 & 129 & 16.0 \\
\hline Higher & 160 & 26.6 & 441 & 73.4 & 601 & 74.4 \\
\hline \multicolumn{7}{|l|}{ Occupation } \\
\hline Agriculture and unskilled labor & 3 & 8.6 & 32 & 91.4 & 35 & 4.3 \\
\hline Business and skilled labor & 26 & 34.2 & 50 & 65.8 & 76 & 9.4 \\
\hline Service & 44 & 24.0 & 139 & 76.0 & 183 & 22.6 \\
\hline Housewives and others & 151 & 29.4 & 363 & 70.6 & 514 & 63.6 \\
\hline \multicolumn{7}{|l|}{ Income ( in 000 taka) } \\
\hline$<30$ & 36 & 22.6 & 123 & 77.4 & 159 & 19.7 \\
\hline $30-60$ & 33 & 28.4 & 83 & 71.6 & 116 & 14.3 \\
\hline $60-90$ & 21 & 33.9 & 41 & 66.1 & 62 & 7.7 \\
\hline $90^{+}$ & 134 & 28.5 & 337 & 71.5 & 471 & 58.3 \\
\hline \multicolumn{7}{|l|}{ Smoking habit } \\
\hline Yes & 31 & 21.8 & 111 & 78.2 & 142 & 17.6 \\
\hline No & 193 & 29.0 & 473 & 71.0 & 666 & 82.4 \\
\hline \multicolumn{7}{|l|}{ Family expenditure ( in 000 taka) } \\
\hline$<40$ & 41 & 21.8 & 147 & 78.2 & 188 & 23.3 \\
\hline $40-50$ & 47 & 32.0 & 100 & 68.0 & 147 & 18.2 \\
\hline $50-60$ & 68 & 36.8 & 117 & 63.2 & 185 & 22.9 \\
\hline $60^{+}$ & 68 & 23.6 & 220 & 76.4 & 288 & 35.6 \\
\hline \multicolumn{7}{|l|}{ Taking restaurant food } \\
\hline Yes & 124 & 26.1 & 351 & 73.9 & 475 & 58.8 \\
\hline No & 100 & 30.0 & 233 & 70.0 & 333 & 41.2 \\
\hline
\end{tabular}




\begin{tabular}{|l|c|c|c|c|c|c|}
\hline Use of can food & & & & & & \\
\hline Yes & 130 & 24.9 & 392 & 75.1 & 522 & 64.6 \\
\hline No & 94 & 32.9 & 192 & 67.1 & 286 & 35.4 \\
\hline Obesity & & & & & & \\
\hline Underweight & 23 & 21.5 & 84 & 78.5 & 107 & 13.2 \\
\hline Normal & 108 & 26.7 & 297 & 73.3 & 405 & 50.1 \\
\hline Overweight & 79 & 30.3 & 182 & 69.7 & 261 & 32.3 \\
\hline Obese & 14 & 40.0 & 21 & 60.0 & 35 & 4.3 \\
\hline Utilization of time & & & & & & \\
\hline Academic activities & 45 & 22.1 & 159 & 77.9 & 204 & 25.2 \\
\hline Reading and watching T.V. & 42 & 24.4 & 130 & 75.6 & 172 & 21.3 \\
\hline Games and sports & 21 & 37.5 & 35 & 62.5 & 56 & 6.9 \\
\hline Paper reading and use of mobile & 69 & 30.9 & 154 & 69.1 & 223 & 27.6 \\
\hline Use of T.V. and mobile & 47 & 30.7 & 106 & 69.3 & 153 & 18.9 \\
\hline Physical exercise & & & & & & \\
\hline Yes & 102 & 21.5 & 312 & 78.5 & 414 & 51.2 \\
\hline No & 122 & 31.0 & 272 & 69.0 & 394 & 48.8 \\
\hline Total & 224 & 27.7 & 584 & 72.3 & 808 & 100.0 \\
\hline
\end{tabular}

Table 1: Distribution of exclusively diabetic adults according to different socioeconomic variables.

risk of diabetes among adults not involved in sedentary activities [R.R.=1.22].

Most of the adults were doing physical exercise (51.2\%) and lower proportion $(24.6 \%)$ of them were experienced of diabetes. Physical exercise had negative significant impact on prevalence of diabetes $\left[\chi^{2}=4.033, \mathrm{p}\right.$-value $\left.=0.045\right]$. Those who did not do physical exercise was at higher risk of diabetes by 32 percent compared to the risk of adults involved in physical exercise [R.R.=1.32].

The percentage of non-smoker was 84.2. But higher proportion of them $(29.0 \%)$ were suffering from diabetes. Insignificant association between smoking habit and prevalence of diabetes was noted $\left[\chi^{2}=2.985, p\right.$ - value $\left.=0.084\right]$ and smokers were not at risk of diabetes [R.R. $=0.75$ [. The study indicated that taking restaurant food was not responsible for diabetes. Because, those who (58.9\%) were used to take restaurant food only 26.1 percent of them were suffering from diabetes. This percentage of diabetic patients among adults not taking restaurant food was 30 percent. This differential in proportions was not significant $\left[\chi^{2}=1.50-5\right.$, $\mathrm{p}$ value $=0.220]$. The risk ratio $[0.87\}$ also did not signify the evidence of risk of diabetes due to habit of taking restaurant food. The percentage of adults taking processed (can) food was 64.6 and 24.9 percent of them were diabetic patients. This analysis also did not show any evidence of risk of diabetes due to habit of taking can food [R.R.=0.76]. However, there was significant association between habit of taking can food and diabetes $\left[\chi^{2}=5.847\right.$, p value $=0.016$.

\section{Factor analysis}

From the analysis presented above it was observed that the variables marital status, age, occupation, expenditure, utilization of time, physical exercise and habit of taking processed food were associated with diabetes. But the study of association does not indicate the most responsible variable for the variation of prevalence of diabetes. The most responsible variable can be detected by factor analysis, where higher value of a factor loading indicates the more responsible variable for the variation in the data set. To identify the most responsible variable factor analysis was done using the variables residence, age, marital status, gender, religion, education, occupation, income, expenditure, smoking habit, habit of taking restaurant and can food, physical exercise, utilization of time and BMI. The inclusion of these variables was satisfactory as KMO $=0.599$ which provided $\chi^{2}=836.768, \mathrm{p}-$ value $=0.000$.

But during factor analysis it was noted that the communalities of some of the variables were less than 0.40 [22]. So these variables were dropped from the analysis. The final included variables were age, gender, marital status, education, occupation, income and expenditure. These variables had the capacity to explain 61.733 percent variation in the data set through the detection of two components. Moreover, the inclusion of variables was justified as $\mathrm{KMO}=0.612, \chi^{2}=626.014$, $\mathrm{p}$ value $=0.000$. The results of the factor analysis were presented in Table 2 . It was observed that the most responsible variable for diabetes was marital status followed by income, expenditure and age. 


\begin{tabular}{|l|c|c|c|}
\hline \multicolumn{1}{|c|}{ Variable } & Communality & $\begin{array}{c}\text { Coefficient of } \\
\text { factor - 1 }\end{array}$ & $\begin{array}{c}\text { Coefficient of } \\
\text { factor -2 }\end{array}$ \\
\hline Age & 0.629 & -0.644 & 0.463 \\
\hline Gender & 0.533 & -0.088 & 0.725 \\
\hline Marital status & 0.739 & 0.772 & -0.378 \\
\hline Education & 0.447 & 0.352 & -0.568 \\
\hline Occupation & 0.490 & 0.628 & 0.308 \\
\hline Income & 0.751 & 0.745 & 0.443 \\
\hline Expenditure & 0.732 & 0.724 & 0.457 \\
\hline
\end{tabular}

Table 2: Results of factor analysis.

\section{Discussion}

The risk of diabetes was reported in both home and abroad [5$11,23,24,26,27]$. It was also reported that diabetes was the major health hazard among Bangladeshi adults [5,6,11,24]. The health problem is created irrespective of age sex, education, occupation, income, expenditure and marital status. It was evident from the present analysis also that married adults had higher risk of diabetes compared to single adults. Variation in the prevalence of diabetes according to the variation of residence, gender and religion was not statistically different. But, male and Muslim adults had higher risk of prevalence of diabetes. Both income and expenditure had positive impacts on the prevalence of diabetes. It also indicated that diabetes is a disease of rich [2]. It may be attributed that rich people had no control in taking rich food which is full of sugar salt and high protein [13]. Because of higher income the families can spend more money which change the lifestyle of the families. Due to this fact diabetes is also called a lifestyle disease [13]. The present study also signified the fact that adults of higher family expenditure had more risk of prevalence of diabetes. The physically inactive adults usually involved in sedentary activity and they are more exposed to the risk of diabetes. The present analysis also supported this phenomenon. However, the habit of taking restaurant food or processed food were not the risk enhancing factors for diabetes.

\section{Conclusion}

The analytical results presented in the paper were done using the data collected from 808 adults of ages 18 years and above by some doctors and nurses from and nearby their working places. As a result most of the investigating (84.2\%) units were from urban area. But the data did not show any evidence of association of residence and prevalence of diabetes. The risk of prevalence of diabetes was similar for both urban and rural residents.

Insignificant association between prevalence of diabetes and gender variation was noted. But female adults (30.3\%) were at higher risk of affecting by diabetes [R.R.=1.23]. Among the adults 89.9 percent were Muslims and 28.4 percent of them were suffering from diabetes. However, religion and prevalence of diabetes were not statistically associated. Still the risk of diabetes was more among Muslims (R.R.=1.29). Among the adults 50.9 percent were married. Marital status and prevalence of diabetes were significantly associated. The married adults were at higher risk of diabe- tes. The prevalence rates of diabetes was significantly different for adults of different ages and those who were of ages 40 years and above were at higher risk of diabetes.

The prevalence of diabetes was higher among illiterate and primary educated adults. But the variation in the prevalence rates according to the variation in the levels of education was not significantly different. However, illiterate adults were at higher risk of affecting by diabetes compared to the risk of educated adults. Significant differences in the prevalence rates were noted among adults of different levels of occupation. The risk of diabetes among businessmen and skilled lobors and service persons was more compared to the risk of other professionals. The prevalence rates of diabetes among adults of different levels of income were not significantly different. But the risk of diabetes among adults of middle income group was slightly more. Significant differences in the prevalence rates were noted for adults of different expenditure levels and adults spending middle level of money as family expenditure were at higher risk of diabetes.

Physical inactivity, involved in sedentary activities and smoking habit were not influencing factors for prevalence of diabetes. But the risk of diabetes was more among the adults of first two above mentioned groups of adults. Habit of taking restaurant food and can food did not enhance the risk of diabetes.

Due to upward social mobility, increased mechanical movement and more involvement in economic activities the prevalence of diabetes cannot be avoided. But the prevalence rate can be controlled, if people can take some initiative

- To control diet by taking healthy and home made food,

- To avoid more sugar based food, salty food and food having unsaturated fat,

- To be careful about the self-care behaviour and avoid smoking,

- To do some physical labor and/or physical exercise or at least walk a while whenever possible.

- To join the blood screening program,

- To adhere the lifelong medical therapy by the patients.

Health planners and social activists can do a lot to encourage the people to follow the above steps.

\section{Bibliography}

1. International Diabetes Federation: Diabetes Atlas, 9TH edition, IDF, Brussels, Belgium (2019).

2. WHO: Fact sheets / detail / obesity-and-overweight (2018).

3. International Diabetes Federation: Country estimates table, Diabetes Atlas,6th edition, IDF (2011).

4. Md Mortuza., et al. "A study on identification of socioeconomic variables associated with no-communicable diseases among Bangladeshi adults". AASCIT 4(2018): 24-29. 
5. Saquib N., et al. "Cardiovascular diseases and type II diabetes in Bangladesh: a systematic review ant meta- analysis of studies between 1995-2010". BMC Public Health 12 (2012): 434.

6. Akter S., et al. "Prevalence of diabetes and pre-diabetes and their risk factors among Bangladeshi adults: A Nationwide survey". Bulletin of the WHO 92 (2014): 204-213 A.

7. Mokdad AH., et al. "Prevalence of obesity, diabetes, and obesity-related health risk factors 2001". JAMA 289 (2003): 76-79.

8. Rabi DM., et al. "Association of socioeconomic status and risk of diabetes related mortality with diabetes prevalence and utilization diabetes care services". BMC Public Health Services Research 6 (2006): 124.

9. WHO. About Chronic Respiratory diseases ,World Health Organization (2018).

10. Abegunde DO and Staniole A. "An estimation of the economic impact of chronic non-communicable diseases in selected countries". WHO workin paper, Geneva, World Health Organization, Department of Chronic Disease and Health Promotion (2006).

11. Fardus J and Bhuyan KC. "Discriminating diabetic patients of some rural and urban areas of Bangladesh: A discriminant analysis approach". Euromediterrean Bio Journal 11 (2016): 134-140

12. Bhuyan KC and Fardus J. "Level of obesity and socioeconomic factors of a group of adult people of Bangladesh: A factor analysis approach". American Journal of Data Mining and Knowledge Discovery 4 (2019): 8-14.

13. Bhuiyan D and Bhuyan KC. "Discriminating Bangladeshi adults by non-communicable diseases". Rehabilitation Science 4.3 (2019): $35-43$.

14. Bhuyan KC., et al. "Socioeconomic factors associated with overweight an obesity : A case study among adult people of Bangladesh". AJSE 16(2017): 119-124.

15. Paymane A and Miranda P. "Images of measurements of obesity". BMJ (2018): 360.

16. Calamusa G., et al.

17. Sistron CL and Garvan CW. "Proportions, odds and risk". Radiology 230.1 (2004): 12-19.

18. Bhuyan KC. "A note on factor analysis applied in medical research". Archives in Biomedical Engineering and Biotechnology 1.4 (2019): 1-3.

19. Bhuyan KC. Multivariate Analysis and its Applications, New Central Book Agency (P) ltd. India (2004).

20. Yotoka T. "Some criteria for bariable selection in factor analysis". Behaviormetrika 13 (1983): 31-45.
21. Syed MS., et al. "Assessing obesity and overweight in a high mountain Pakistani population". Tropical Medicine and International Health 9 (2004): 526-532.

22. Jain K. "Value of communality". Amity Business School (2018).

23. Bhuyan KC. "Factors responsible for non-communicable diseases among Bangladeshi adults". Biomedical Journal of Scientific and Technical Research 20 (2019): 14742-14748.

24. Bhuyan KC., et al. "Relationship between socioeconomic factors and diabetes among urban and rural people of Bangladesh". Global Journal of Quantitative Science 3 (2016).

25. Bertino B., et al. "Obesity and related diseases: an epidemiological study in Eastern Sicily". Minerva Gastroenterologica e Dietologica 52 (2006): 379-385.

26. Prakashchandra RD and Naido DP. "Glycemic control profile in diabetes patients: A sub-analysis of the phoenix lifestyle project". Euromediterranean Biomedical Journal 11 (20116): 33-39.

27. Hussain A., et al. "Type II diabetes in rural and urban population: diverse prevalence and associated risk factors in Bangladesh". Diabetic Medicine 22 (2005): 931-936.

\section{Assets from publication with us}

- Prompt Acknowledgement after receiving the article

- Thorough Double blinded peer review

- Rapid Publication

- Issue of Publication Certificate

- High visibility of your Published work

Website: https://www.actascientific.com/

Submit Article: https://www.actascientific.com/submission.php Email us: editor@actascientific.com

Contact us: +919182824667 